therapy except in the RA scenario with severe disease activity/ severity. For mild disease activity/severity: 1) a surprisingly high percent employed NSAID and/or CS alone; 2) half of the rheumatologists did not prefer MTX, gold, azathioprine, cyclosporine or any of the newer DMARDs (leflunomide, etanercept, infliximab) in this broad RA patient population. For the first-line treatment of early RA, aggressive DMARD therapy is not universally employed by all rheumatologists in the regions studied.

\section{OP0119 RADIOLOGICAL PROGRESSION IN PATIENTS WITH EARLY RHEUMATOID ARTHRITIS IS SIGNIFICANTLY RETARDED BY COMBINATION THERAPY WITH METHOTREXATE AND CYCLOSPORIN-A COMPARED TO CYCLOSPRIN-A ALONE}

${ }^{1} \mathrm{AH}$ Gerards, RB Landewé ${ }^{2},{ }^{1} \mathrm{AP}$ Prins, ${ }^{3} \mathrm{GA}$ Bruijn, ${ }^{2} \mathrm{HS}$ Goei The, ${ }^{1} \mathrm{BA}$ Dijkmans. ${ }^{1}$ Rheumatology, Vrije Universiteit Medical Centre, Amsterdam; ${ }^{2}$ Rheumatology, University Hospital, Maastricht; ${ }^{3}$ Rheumatology, Medisch Centrum, Leeuwarden, The Netherlands

10.1136/annrheumdis-2001.1220

Background Cyclosporin-A (CsA) added to low dose methotrexate (MTX) in patients with advanced rheumatoid arthritis (RA) is clinically superior to MTX alone. ${ }^{1}$ The potential of CsA and MTX to inhibit radiological progression has not been established yet.

Objectives To assess in patients with early, active and potentially aggressive RA whether the combination of CsA and MTX results in less radiological progression as compared to CsA alone.

Design A randomised double blind placebo controlled trial of 48 weeks duration.

Methods 120 patients with active RA: mean age 52 yrs, mean disease duration 3 months, 95\% rheumatoid factor positive, $49 \%$ erosions and/or joint space narrowing. Patients received CsA and MTX or CsA and placebo. MTX was started at 7.5 $\mathrm{mg} /$ week, and was increased to $15 \mathrm{mg} /$ week after 16 weeks. CsA was started at $2.5 \mathrm{mg} / \mathrm{kg} / \mathrm{day}$, and was increased to a maximum of $5 \mathrm{mg} / \mathrm{kg} /$ day. Plain X-rays of hands and feet were obtained at week 0 and week 48 and were read in chronological order by two independent observers, blind for the study medication, using the Larsen-modified Larsen score. ${ }^{2}$

Results The Table 1 summarises the Larsen Score of patients in which 2 sets of films were available.

\begin{tabular}{lll} 
Abstract OP0119 Table 1 & & \\
\hline & Baseline & Change from baseline \\
\hline CsA and MTX $(\mathbf{n}=58)$ & $2.0(0.0-5.5)^{*}$ & $4.0(1.0-10.5)$ \\
CsA and placebo $(\mathbf{n}=57)$ & $2.5(0.5-5.5)$ & $10.0(3.5-13.3)$ \\
p-value for the difference** & & 0.004 \\
\hline *Median (interquartile range). & & \\
${ }^{* *}$ Mann-Whitney two-sample test. & &
\end{tabular}

Conclusion CsA and MTX significantly retards radiological progression in comparison with CsA alone in patients with early, active and potentially aggressive RA.

\section{REFERENCES}

1 Tugwell. NEJM 1995;333:137-41

2 Larsen. J Rheum. 1995;22(10):1974-5
OP0120 CAUSE OF DEATH IN A PROSPECTIVE STUDY OF RA PATIENTS: DO RHEUMATOLOGY DRUGS PLAY A PART?

${ }^{1} S$ Stafford, ${ }^{1}$ CA Mayes, 'A Young, ${ }^{2} \mathrm{P}$ Williams. ${ }^{1}$ Rheumatology, St Albans City Hospital, St Albans; ${ }^{2}$ Rheumatology, Medway District Hospital, Gillingham, UK

10.1136/annrheumdis-2001.1221

Background Few prospective studies in RA have reported on the occurrence of comorbid conditions and mortality, and what proportion could be either disease or treatment related. The Early Rheumatoid Arthritis Study (ERAS) has prospective outcome data on patients followed for as long as 13 years.

Objectives To classify the cause of death and investigate any possible relationship with second line (disease modifying), steriodal or non steroidal anti-inflammatory drugs (NSAIDs).

Methods Consecutive patients with RA of less than two years duration have been recruited into an inception cohort from 9 rheumatology units. 1500 patients have been recruited into the study, prior to the use of second line drugs within 2 years of onset of symptoms of RA. Standard clinical and laboratory data were recorded yearly. Details of medication have been collected prospectively. Nearly all patients received non steriodal antiinflammatory drugs (NSAIDs) at some stage, $84 \%$ received second line (disease modifying) drugs and 4\% steroids alone. 166 deaths have been recorded from clinical notes, death certificates and the NHS Central Register (NHSCR). Cause of death has been catergorised according to both aetiology and main organ involvement.

Results Major causes of death in 166 patients (males $n=71$ and females $\mathrm{n}=95)$ were as follows: cardiovascular disease $(\mathrm{n}=$ $56,33.7 \%)$, cerebrovascular $(\mathrm{n}=14,8.4 \%)$, malignancy $(\mathrm{n}=$ $45,27.1 \%)$ and respiratory $(\mathrm{n}=32,19.3 \%)$. Pulmonary infections were recorded in 22 of the latter, Pulmonary Fibrosis in 6 ( 2 on methotrexate, but present prior to start of therapy), and others $(n=4) .19$ miscellaneous conditions included gastrointestinal haemorrhage ( $\mathrm{n}=4$, NSAID related in 3 ) and septicaemia ( $\mathrm{n}=5,2$ on steroids and 1 with neutropenia probably methotrexate induced).

Conclusion No direct link could be established between cause of death and rheumatoid disease or drug therapy in most patients, except those with Pulmonary Fibrosis (4\%), and in 6 patients where drug therapy could have been a contributory factor to cause of death.

\section{OP0121 ENBREL ${ }^{\circledR}$ (ETANERCEPT) VS. METHOTREXATE (MTX) IN EARLY RHEUMATOID ARTHRITIS (ERA TRIAL): TWO- YEAR FOLLOW-UP}

${ }^{1} \mathrm{M}$ Genovese, ${ }^{2} \mathrm{RW}$ Martin, ${ }^{3} \mathrm{R}$ Fleischmann, ${ }^{4} \mathrm{E}$ Keystone, ${ }^{5}$ J Bathon, ${ }^{6} \mathrm{G}$ Spencer-Green, ${ }^{6} \mathrm{~B}$ Finck. ${ }^{1}$ Department of Medicine/lmmunology and Rheumatology, Stanford University School of Medicine, Palo Alto; ${ }^{2}$ Clinical Rheumatology, Michigan State University, Grand Rapids; ${ }^{3}$ Rheumatology Associates, Metroplex Clinical Research Center, Dallas; ${ }^{4}$ Center for Advanced Therapeutics, Mount Sinai Hospital, Toronto, Canada; ${ }^{5}$ Asthma and Allergy Center, Johns Hopkins University, Baltimore; ${ }^{6}$ Clinical Developent, Immunex Corporation, Seattle, USA

10.1136/annrheumdis-2001.1222

Background The first year of this 2-year study of patients with early erosive RA (mean disease duration 1 year) demonstrated that ENBREL $25 \mathrm{mg}$ twice weekly gave a more rapid clinical response and was more effective in preventing erosions than high dose (median $20 \mathrm{mg} / \mathrm{wk}$ ) oral MTX. ${ }^{1}$ 
Objectives To evaluate safety, clinical improvement, and radiographic outcomes in patients receiving ENBREL or MTX for up to 2 years.

Methods Patients enrolled in this 2-year study continued to receive the therapy to which they had been randomised in an open-label fashion after the study was unblinded (at a mean of 17.3 months). The 2-year endpoints were ACR responses (using last on-drug observation carried forward analyses) and change in Sharp score. Readers were blinded to treatment and chronological order of the x-rays. All 632 patients were included in the analyses.

Results 154 of 207 patients (74\%) who received ENBREL 25 mg completed 2 years of treatment, compared to 129 of 217 patients (59\%) who received MTX. Twice as many patients (12\%) discontinued MTX for adverse events as did those taking ENBREL. The ACR 20 response at 2 years was $72 \%$ in those randomised to ENBREL and 59\% in those randomised to MTX $(\mathrm{P}=0.005)$. Radiographic evaluations demonstrated that ENBREL $25 \mathrm{mg}$ was superior to MTX in arresting radiographic progression over the 2-year period. Mean (median) changes in total Sharp score were $1.3(0)$ and $3.2(0.5)$ units in the ENBREL $25 \mathrm{mg}$ and MTX groups, respectively $(\mathrm{P}=0.001)$ and changes in erosion score were $0.7(0)$ and $1.9(0)$ units, respectively $(\mathrm{P}=0.001)$. ENBREL $25 \mathrm{mg}$ prevented radiographic progression in $63 \%$ of patients, compared to $51 \%$ of MTX patients who did not progress $(\mathrm{P}=0.017)$. ENBREL $25 \mathrm{mg}$ was also superior to the $10 \mathrm{mg}$ dose in inhibiting radiographic progression. Significantly more ENBREL $25 \mathrm{mg}$ patients than MTX patients had a clinically meaningful (at least 0.5 units) improvement from baseline in HAQ disability score. ENBREL continued to be well tolerated with over 2 years of exposure.

Conclusion This 2-year study demonstrated that ENBREL was superior to MTX in reducing clinical signs and symptoms of RA and inhibiting radiographic progression.

\section{REFERENCE}

1 Bathon JM, Martin RW, Fleischmann RM, et al. NEJM 2000;343:1586-93

\section{SLE - Etiology and pathogenesis/Animal models}

\section{AB0069 ANTI BETA 2 GLYCOPROTEIN ANTIBODIES AND THROMBOSIS IN SLE PATIENTS}

MA Mansour, M Badr, H El Bebawi, A El Ghobarey. Rheumatology, Meadi Armed Force Hospital, Cairo, Egypt

10.1136/annrheumdis-2001.1223

\section{Background}

Objectives Beta 2 glycoprotein was identified as a cofactor for the binding of antiphospholipid antibodies. Anticardiolipin antibodies were found to correlate with thrombosis in SLE patients. We measured the subclasses of anti B2 GP1 in LSE patients with or without history of thrombosis.

Methods Fourty four SIE patients with mean ( \pm SD) age of 26.7 \pm 9.9 ) years, nine of whom had a history of vascular thrombosis along with 30 healthy age and sex matched normal control subjects were studied.

Results There was a correlation between the presence of IgG anti B2 GP I and the incidence of thrombosis $(\mathrm{P}<0.05)$, There was, also, a positive correlation between IgG anti B2 GPt and
IgG aCL antibodies and a negative correlation between IgG anti B2 GP1 and thrombocytopenia. However, serum levels of IgG and $1 \mathrm{gM}$ anti B2GPI were increased in patients who had positive LAC activity. This thesis confirm the pathologic role of $\mathrm{IgG}$ anti B 2 GP1 (and not 1gM) in the incidence of thrombosis in SLE patients. Also, its relationship to the presence of anti ds DNA antibodies, anti CLA and lupus anticoagulant in SIE is discussed.

Conclusion

\section{AB0070 THE EFFECT OF PROLACTIN ON DISEASE ACTIVITY IN SLE}

LC Te Boome, PM Welsing, AA Eijsbouts, FH Van den Hoogen. Rheumatology, University Medical Center, Nijmegen, Netherlands

10.1136/annrheumdis-2001.1224

Background Prolactin, a hormone with immunomodulatory effects, possible plays a role in the disease activity of Systemic Lupus Erythematosus (SLE). Results of studies are contradictory regarding the correlation between hyperprolactinemia and disease activity.

Objectives To establish whether determination of prolactin is helpful in assessing disease activity in SLE by reviewing relevant literature.

Methods Studies were identified through Medline search. Also references from these articles were reviewed.

Results Ten articles that sought to establish a relationship between prolactin and SLE activity were identified.

Number of patients in the studies varied from 29 to 192 , aged 16-73 years, and the percentage of elevated serum prolactin levels in SLE patients was between $2.2-40 \%$. The SLEDAI was used as disease activity index in $7 / 10$ studies. The presence of conditions known to be associated with hyperprolactinemia were either reported or excluded. Steroids treatment was accepted in all studies, DMARDs were used in $8 / 10$ studies. In $5 / 10$ studies bloodsamples were collected midmorning and in 4/ 10 patients had to fast. Single measurement of serum prolactin concentration and disease activity was done in 6 studies. The other 4 studies had 2-4 measurements per patient. Pearson?s correlation coefficient was the used statistical analysis in $7 / 10$ studies. A relation between prolactin and disease activity was reported in one study. The number of included patients in the studies was small and different statistical methods were used.

Conclusion The correlation between serum prolactin levels and disease activity is still uncertain. A cross-sectional as well as longitudinal study with using the correct statistics, power calculation and proper recording of secondary causes of elevated prolactin and medication need to be done.

\section{FRI0083 ELEVATED IL-16 LEVEL IS A NON-GENETIC CHARACTERISTIC OF PATIENTS WITH SEVERE SYSTEMIC LUPUS ERYTHEMATOSUS}

${ }^{1}$ LR Lard, ${ }^{2} \mathrm{BO}$ Roep, ${ }^{1}$ TW Huizinga. ${ }^{1}$ Rheumatology, ${ }^{2}$ Immunohaematology and Bloodbank, Leiden University Medical Centre, Leiden, Netherlands

10.1136/annrheumdis-2001.1225

Background IL-16, origanilly named lymphocyte chemoattractant factor, is a cytokine which is mainly produced by $\mathrm{CD}^{+} \mathrm{T}$ cells. Several reports have described that increased levels of IL- 